\title{
O INHANDUVÁ (PROSOPIS AFFINIS SPRENG.) NO RIO GRANDE DO SUL. 6 - DESCRIÇÃO DE UM PARQUE NATURAL NA VÁRZEA DO RIO IBICUí, MUNICÍPIO DE CACEQUI ${ }^{1}$
}

\author{
JOSÉ NEWTON CARDOSO MARCHIORI² FABIANO DA SILVA ALVES ${ }^{3}$
}

\section{RESUMO}

É descrito um parque natural de inhanduvá (Prosopis affinis Spreng.) existente na planície de inundação do rio Ibicuí, município de Cacequi. A presente ocorrência, em área disjunta, reforça a interpretação da planície adjacente ao rio Ibicuí como rota imigratória para a espécie.

Palavras-chave: Prosopis affinis, Fitogeografia, município de Cacequi, Rio Grande do Sul.

\section{SUMMARY}

[Prosopis affinis Spreng. in Rio Grande do Sul state, Brazil. 6 - Description of a natural stand on Ibicui river's flood plain, municipality of Cacequi].

A natural stand of Prosopis affinis Spreng. is described, growing on the flood plain of Ibicui river (municipality of Cacequi, Rio Grande do Sul state, Brazil). This occurrence in a disjunct area gives additional force to the understanding of Ibicui river's adjacent plain as an immigratory route to the studied species.

Key words: Prosopis affinis, Phytogeography, municipality of Cacequi, Rio Grande do Sul state, Brazil.

\section{INTRODUÇÃO}

Com a descrição dos parques de inhanduvá do Jarau (Alves \& Marchiori, 2010), do Loreto (Marchiori et al., 2010) e da várzea do rio Santa Maria (Alves \& Marchiori, 2011), não mais se sustentam, por equivocadas, as referências bibliográficas que limitavam a distribuição natural desta espécie, no Rio Grande do Sul, à área do "Parque Estadual do Espinilho", em Barra do Quaraí (Galvani, 2003; Galvani \& Baptista, 2003), ou à planície aluvial existente entre esta cidade e Uruguaiana (Veloso \& Góes-Filho, 1982). Sobre este tema, aliás, cabe salientar que Marchiori et al. (1983, 1985A, 1985B) já referiam a presença da espécie em "pontos isolados da Campanha do Sudoeste" em meados dos anos 1980, "notadamente ao longo da bacia do rio Ibicuî".

1 Recebido em 25-1-2011 e aceito para publicação em 18-2-2011.

2 Engenheiro Florestal, Dr. Professor Titular do Departamento de Ciências Florestais, UFSM. Bolsista de Produtividade em Pesquisa ( $\mathrm{CNPq}$ - Brasil).

${ }^{3}$ Biólogo, MSc. Professor da Universidade da Região da Campanha (URCAMP - Alegrete). Doutorando do Programa de Pós-Graduação em Engenharia Florestal, UFSM.
Ao descrever um terceiro parque natural de inhanduvá na região, desta vez no município de Cacequi, o presente estudo visa a contribuir para o conhecimento da Província do Espinhal no Rio Grande do Sul, bem como reforçar a interpretação das planícies sedimentares adjacentes ao rio Ibicuí como rota imigratória da espécie em direção ao interior do Estado, a partir da foz deste rio no Uruguai.

\section{DESCRIÇÃO DO PARQUE}

Situado na planície de inundação da margem esquerda do rio Ibicuí, no $3^{\circ}$ distrito do município de Cacequi, o parque de inhanduvá em estudo se encontra na Fazenda Santa Fé, propriedade da família Mezzomo. Relativamente longo (cerca de $1500 \mathrm{~m})$ e estreito $(50$ a $300 \mathrm{~m})$, o parque se encontra a $86 \mathrm{~m}$ de altitude e a $1400 \mathrm{~m}$ do rio Ibicuí, do qual se separa por cordões de mata ciliar, pequenas lagoas e banhados. Como referência geográfica, citam-se as coordenadas de $29^{\circ} 47^{\prime} 37^{\prime \prime}$ S e 54'59' 50'W (Figura 1).

De origem sedimentar, o terreno é formado por depósitos aluviais, com areia grossa até fina e sedimentos síltico-argilosos. O solo, definido como Planossolo Háplico Eutrófico Arênico 


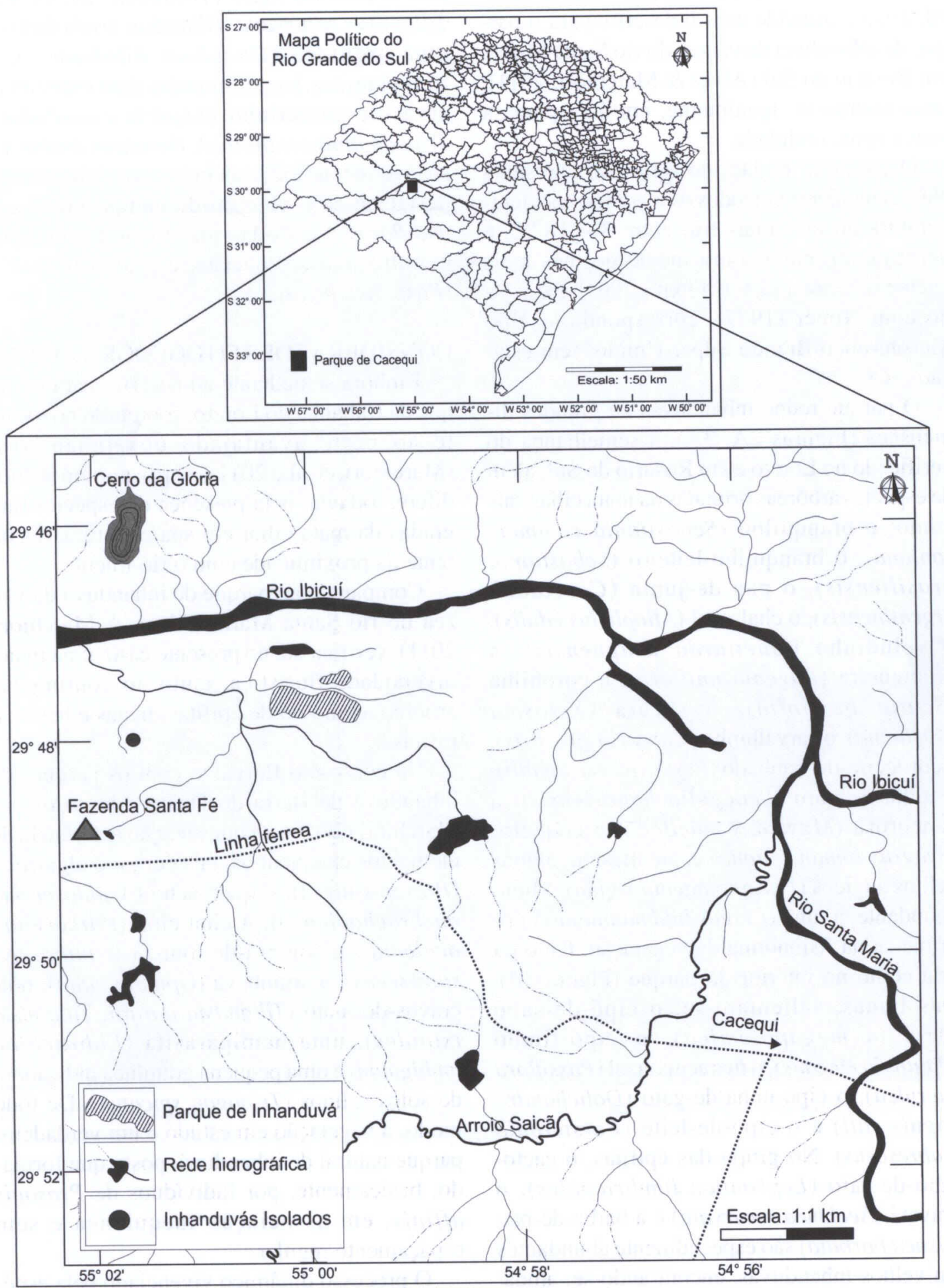

FIGURA 1 - Mapa de localização do Parque de Inhanduvá da várzea do rio Ibicuí, município de Cacequi. 
(Streck et al., 2008) ou Unidade Vacacaí (Brasil, 1973), coincide com o descrito para o parque de inhanduvá da várzea do rio Santa Maria, em Rosário do Sul (Alves \& Marchiori, 2011), encontrando-se, igualmente, em área plana a suavemente ondulada.

O clima da região, do tipo Cfa, apresenta chuvas regulares em todos os meses do ano, temperatura do mês mais frio entre $3-18{ }^{\circ} \mathrm{C}$, e verões com temperatura média do mês mais quente superior a $22^{\circ} \mathrm{C}$ (Moreno, 1961). De acordo com Nimer (1977), corresponde ao tipo Mesotérmico Brando Super-Úmido, sem estação seca.

O parque reúne inhanduvás de grandes dimensões (Figuras 2A, 3A), à semelhança do verificado no Loreto e em Rosário do Sul, além de espécies arbóreas oriundas da mata ciliar, tais como: o branquilho (Sebastiania commersoniana), o branquilho-leiteiro (Sebastiania brasiliensis), o pau-de-junta (Coccoloba argentinensis), o chal-chal (Allophylus edulis), o veludinho (Guettarda uruguensis), a pitangueira (Eugenia uniflora), a coronilha (Scutia buxifolia), o sucará (Xylosma tweediana), o carvalhinho (Casearia silvestris), a corticeira-do-banhado (Erythrina cristagalli), a unha-de-gato (Senegalia bonariensis), a cancorosa (Maytenus muelleri), o coqueiro (Syagrus romanzoffiana) e, até mesmo, alguns velhos angicos (Parapiptadenia rigida). Muito abundante, a tuna (Cereus hildmannianus) imprime-se na fisionomia da vegetação, tanto na orla como no interior do parque (Figura 3B). Das lianas, salientam-se: o cipó-de-sapo (Araujia megapotamica), o cipó-timbó (Paullinia elegans), o maracujá-azul (Passiflora caerulea), o cipó-unha-de-gato (Dolichandra unguis-cati) e o cipó-de-leite (Forsteronia glabrescens). No grupo das epífitas, o cactorabo-de-rato (Lepismium lumbricoides), o gravatá (Aechmea recurvata) e a barba-de-pau (Usnea barbata) são especialmente abundantes em velhos inhanduvás, encontrando-se, ainda, três pteridófitas (Microgramma mortoniana; Pleopeltis pleopeltifolia; Pleopeltis squalida), três cravos-do-mato (Tillandsia aeranthos; Tillandsia recurvata; Tillandsia tricholepis) e uma orquídea (Oncidium bifolium). Das hemiparasitas, foram anotadas duas espécies de ervas-de-passarinho (Ligaria cuneifolia e Tripodanthus acutifolius). No estrato herbáceo, notavelmente escasso junto aos inhanduvás, destacam-se o alecrim-do-campo (Vernonia nudiflora), a erva-da-vida (Heimia salicifolia) e, entre outras Poaceae, a grama-forquilha (Paspalum notatum).

\section{CONSIDERAÇÕES FITOGEOGRÁFICAS}

Embora semelhante ao descrito para o Parque da Cabanha do Loreto, sobretudo no tocante ao porte avantajado dos inhanduvás (Marchiori et al., 2011), o parque em estudo difere, todavia, pela presença de espécies imigradas da mata ciliar em sua estrutura, decorrente da proximidade com o rio Ibicuí.

Comparado ao parque de inhanduvá da várzea do rio Santa Maria (Alves \& Marchiori, 2011), verifica-se, no presente caso, uma maior diversidade florística, tanto no contingente arbóreo, como no de epífitas, lianas e hemiparasitas.

No confronto florístico com os parques de inhanduvá de Barra do Quaraí, descritos por Marchiori (2004), chama atenção a ausência de elementos chaquenhos, tais como: o algarrobo (Prosopis nigra), o quebracho (Aspidosperma quebrachoblanco), a cina-cina (Parkinsonia aculeata), a sombra-de-touro (Acanthosyris spinescens), a arumbeva (Opuntia elata), dois cravos-do-mato (Tillandsia duratii, Tillandsia ixioides), uma hemiparasita (Eubrachion ambiguum) e uma pequena gramínea indicadora de solos salinos (Tripogon spicatus). De todo modo, a vegetação em estudo é um verdadeiro parque natural de inhanduvá, posto que formado, basicamente, por indivíduos de Prosopis affinis, em associação inequiânea e sem espaçamento regular.

O processo dinâmico vivenciado pela espécie se pode reconhecer, muito claramente, na vegetação em estudo: como árvore pioneira, o 

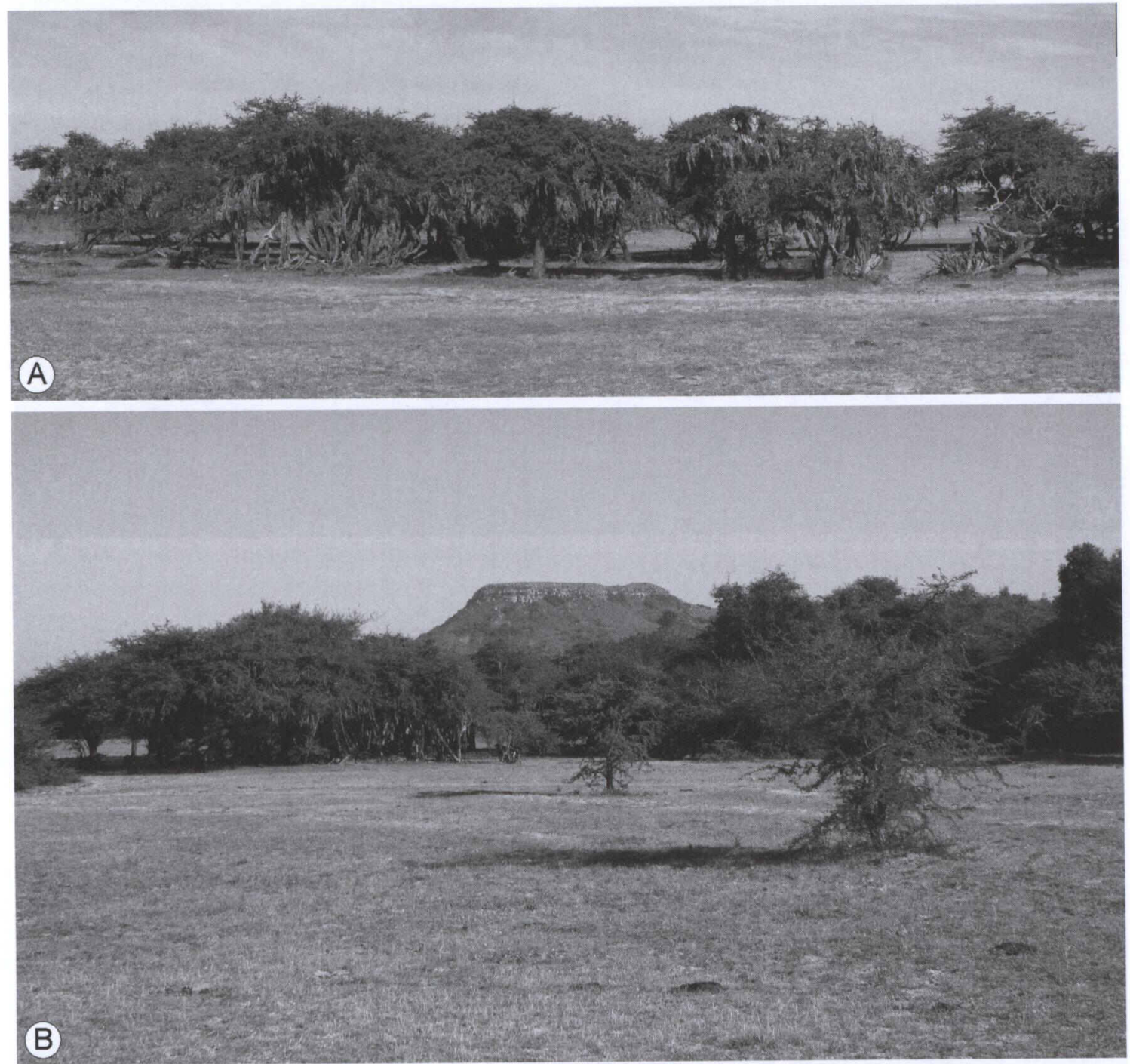

FIGURA 2 - Dois aspectos do Parque de Inhanduvá de Cacequi. A - Vista parcial. B - Detalhe do parque, com o Cerro da Glória (ao fundo) e inhanduvás jovens em primeiro plano. 

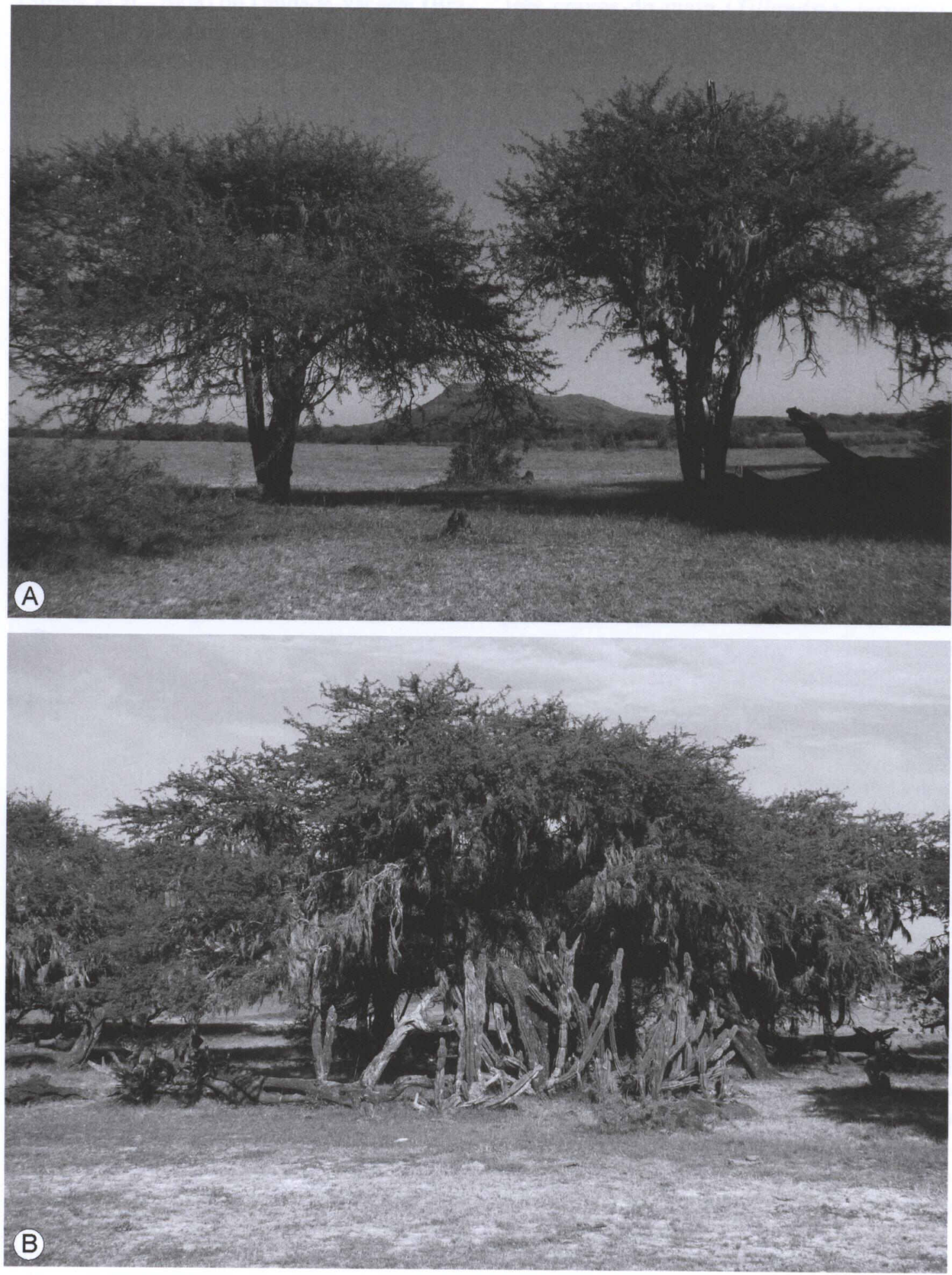

FIGURA 3 - Dois inhanduvás adultos, com o Cerro da Glória ao fundo. B - Inhanduvá adulto, troncos de inhanduvás mortos e tunas (Cereus hildmannianus). 
inhanduvá favorece a entrada de espécies oriundas da mata ciliar no interior do parque, as quais acabam por comprometer, mediante sombreamento, a sobrevivência do próprio inhanduvá na estrutura da vegetação. Deste modo, os indivíduos de Prosopis affinis tendem a desaparecer no interior do parque com o crescimento de árvores mais altas, tais como o angico, conquistando espaço, todavia, no campo adjacente, desde que sob condições edáficas favoráveis (Figura 2B). Na área em estudo (Fazenda Santa Fé), a planície de inundação ainda se estende por algumas centenas de metros, além do parque, de modo que a principal ameaça ao inhanduvá reside na eventual destinação da várzea adjacente para cultivos agrícolas, notadamente o arroz. Recomenda-se, portanto, a não utilização de uma faixa de terra junto ao parque de inhanduvá, com vistas a favorecer o processo dinâmico acima exposto e garantir a preservação da espécie na região.

Dada a estreita vinculação do inhanduvá com planícies sedimentares, chega-se à conclusão de que o largo vale do rio Ibicuí funcionou como rota imigratória para a espécie, a partir do extremo oeste do Rio Grande do Sul, por ser a única via, nesta condição geomorfológica, a transpor a barreira do Planalto da Campanha.

Os parques de inhanduvá do Loreto, em São Vicente do Sul, bem como o da várzea do rio Santa Maria, em Rosário do Sul, constituem pontas-de-lança no avanço da espécie pelas planícies aluviais da bacia do Ibicuí (Figura 4). Junto com o parque presentemente descrito, estas três áreas disjuntas confirmam a distribuição geográfica referida por Marchiori et al. (1983, 1985A, 1985B), contestando definitivamente, ao mesmo tempo, as referências bibliográficas que limitavam Prosopis affinis, no Rio Grande do Sul, ao município de Barra do Quaraí (Galvani, 2003; Galvani \& Baptista, 2003), ou à planície aluvial existente entre esta cidade e Uruguaiana (Veloso \& Góes-Filho, 1982).

\section{REFERÊNCIAS BIBLIOGRÁFICAS}

ALVES, F. da S.; MARCHIORI, J.N.C. O inhanduvá (Prosopis affinis Spreng.) no Rio Grande do Sul. 2 - Ocorrência natural na região do Jarau, Quaraí. Balduinia, Santa Maria, n. 25, p. 1-9, 2010.

ALVES, F. da S.; MARCHIORI, J.N.C. O inhanduvá (Prosopis affinis Spreng.) no Rio Grande do Sul. 5 - Ocorrência natural na várzea do rio Santa Maria, Rosário do Sul. Balduinia, Santa Maria, n. 27, p. 1-7, 2011.

BRASIL. Ministério da Agricultura. Departamento Nacional de Pesquisa Agropecuária. Divisão Pedológica. Levantamento de reconhecimento dos solos do Estado do Rio Grande do Sul. Recife, 1973. 471 p. (DNPEA. Boletim Técnico, 30). GALVANI, F.R. Vegetação e aspectos ecológicos do Parque Estadual do Espinilho, Barra do Quaraí, RS. Porto Alegre: Universidade Federal do Rio Grande do Sul, 2003. 132 f. Tese de Doutorado (Programa de Pós-Graduação em Botânica).

GALVANI, F.R.; BAPTISTA, L.R. de M. Flora do Parque Estadual do Espinilho - Barra do Quaraí/RS. Revista da FZVA, Uruguaiana, v. 10, n. 1, p. 42-62, 2003.

MARCHIORI, J.N.C. Fitogeografia do Rio Grande do Sul. Campos Sulinos. Porto Alegre: EST, 2004. $110 \mathrm{p}$.

MARCHIORI, J.N.C.; ALVES, F. da S.; PAZ, E.A. O inhanduvá (Prosopis affinis Spreng.) no Rio Grande do Sul. 3-Parque da Cabanha do Loreto, São Vicente do Sul. Balduinia, Santa Maria, n., 25, p. 22-31, 2010.

MARCHIORI, J.N.C.; DURLO, M.A.; ALVES, F. da S. O inhanduvá (Prosopis affinis Spreng.) no Rio Grande do Sul. 4 - Aspectos botânicovegetacionais e morfométricos do Parque do Loreto, São Vicente do Sul. Balduinia, Santa Maria, n. 26, p. 8-18, 2011.

MARCHIORI, J.N.C.; LONGHI, S.J.; GALVÃO, L. $\mathrm{O}$ gênero Prosopis L. (Leguminosae Mimosoideae) no Rio Grande do Sul. Ciência e Natura, Santa Maria, n. 5, p. 171-177, 1983.

MARCHIORI, J.N.C.; LONGHI, S.J.; GALVÃO, L. Composição florística e estrutura do parque de inhanduvá no Rio Grande do Sul. Rev. Centro de Ciências Rurais, Santa Maria, v. 15, n. 4, p. 319-334, 1985A. 


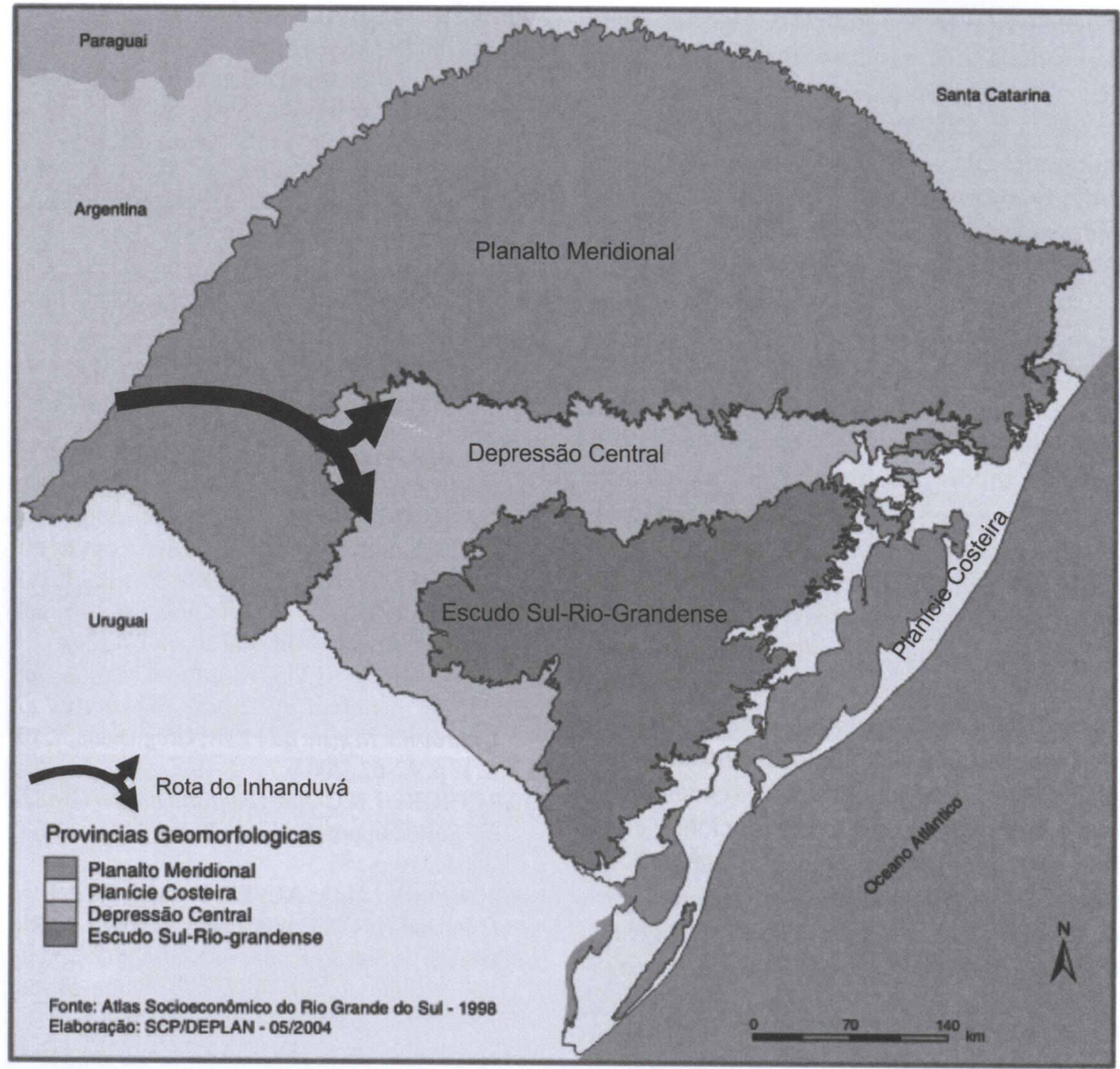

FIGURA 4 - Rota imigratório do Inhanduvá pelo vale do rio Ibicuí.

MARCHIORI, J.N.C.; LONGHI, S.J.; GALVÃO, L. Estrutura fitossociológica de uma associação natural de parque inhanduvá com quebracho e cinacina, no Rio Grande do Sul. Ciência e Natura, Santa Maria, n. 7, p. 147-162, 1985B.

MORENO, J.A. Clima do Rio Grande do Sul. Porto Alegre: Secretaria da Agricultura - Diretoria de Terras e Colonização, 1961. 42 p.

NIMER, R. Clima. Geografia do Brasil. Região Sul. Rio de Janeiro: IBGE, 1977. p. 35-79.
STRECK, E.V.; KÄMPF, N.; DALMOLIN, R.S.D.; KLAMT, E.; NASCIMENTO, P.C. do; SCHNEIDER, P.; GIASSON, E.; PINTO, L.F.S. Solos do Rio Grande do Sul. Porto Alegre: EMATER/RS - ASCAR, 2008. 222p.

VELOSO, H.P; GÓES-FILHO, L. Fitogeografia brasileira. Classificação fisionômico-ecológica da vegetação neotropical. Salvador: Projeto RADAMBRASIL, 1982.80 p. (Boletim Técnico, Ser. Vegetação, v. 1). 